\title{
Correspondence
}

Editor: Greg Wilkinson

Contents: Elderly offenders/Calcium therapy for neuroleptic-induced extrapyramidal symptoms/Significant results in tables/Progress towards DHSS targets for community care/Therapy-resistant depression/The viral theory of schizophrenia/Psoriasis and lithium/General practice patients on longterm psychotropic drugs/P3 and CT scan in patients with chronic schizophrenia/Unilateral auditory hallucinations/Inadequate seizures with electroconvulsive therapy/Diethylproprion, buproprion, and psychoses/Self-inflicted eye injuries/ Psychosomatic medicine and contemporary psychoanalysis/Vitamin B12 in psychotic depression/ Clinical dementia rating/Delusional AIDS and depression/Mianserin and mania/Is castration too "barborous" for rapists?

\section{Elderly Offenders}

SIR: Dr Lynch's comments on our paper (Journal, July $1988,153,122)$ are most welcome. We had hoped to highlight a problem for which we believed too little appropriate management is available, and his letter provides further evidence that this is the case.

Dr Lynch is by no means the first to challenge the assumption that criminality decreases with age. Greenberg (1983) goes further still, and includes among the distorting factors the tendency of the young to commit crimes in groups, the improved skills in avoiding detection among the elderly, and annual cohort effects. Nevertheless, the overall discrepancy between the contribution to crime by people of 55 and over compared with those of, say, 15-25 is so great that it seems unlikely that these are sufficient explanations and that there must also be a real difference. Furthermore, a number of longitudinal studies within cohorts on both sides of the Atlantic (summarised by Cline, 1980), while not generally following the subjects beyond the age of 30 , do all suggest a genuine decline with age with most types of offending. Drunkenness and drink-related offending seem the sole areas of important deviation from this position. While defending the generally accepted view of the changing patterns of criminal behaviour with age, none of this detracts from $\mathrm{Dr}$
Lynch's point that almost certainly, more of the elderly are involved in offending than appear in official statistics.

Dr Lynch's concern about the poverty of psychiatric provision is in direct line with ours. The vast majority of our over-55 sample had a history of previous psychiatric treatment, and a bare majority had active symptoms of disorder on admission to prison; very few went on to treatment. Dr Lynch's figures are much more representative of the true levels of neglect, as he gives the proportion of all identified elderly offenders who receive a psychiatric opinion, and not just the minority on custodial remand as was the case in our sample. How many fewer still would have actually benefited from the opinion hardly bears thinking about. It would be valuable to hear from psychiatrists in areas that offer a more constructive approach to the elderly offender than Chester, Liverpool, and Greater London.

Pamela Taylor

Institute of Psychiatry

Denmark Hill

London SE5 8AF

Bexley Hospital

JANET PARROTT

\section{References}

CLINE, H. F. (1980) Criminal behaviour over the life span. In Constancy and Change in Human Development (eds O. G. Brim \& J. Kagan), pp. 641-674. Cambridge, MA: Harvard University Press.

GrEenBerg, D. (1983) Age and crime. In Encyclopedia of Crime and Justice (ed. S. H. Kadish), pp. 30-35. New York: Macmillan.

\section{Calcium Therapy for Neuroleptic-Induced Extrapyramidal Symptoms}

SIR: I read with great interest the correspondence by Drs Fernando and Manchanda on calcium therapy for neuroleptic-induced extrapyramidal symptoms (EPS) and the report of successful treatment of two cases of EPS whose symptoms disappeared with calcium (Journal, May 1988, 152, 722-723).

We used calcium in the 1960 s for drug-induced Parkinsonism, with mixed success. I reported a patient with retinitis pigmentosa and psychosis 